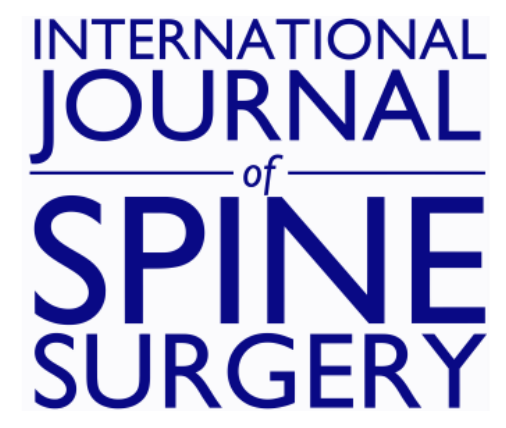

\title{
Reliability of the Planned Pedicle Screw Trajectory versus the Actual Pedicle Screw Trajectory using Intra-operative 3D CT and Image Guidance
}

Catherine A. Miller, Charles G. Ledonio, Matthew A. Hunt, Farhan Siddiq and David W. Polly, Jr

Int J Spine Surg 2016, 10 ()

doi: https://doi.org/10.14444/3038

http://ijssurgery.com/content/10/38

This information is current as of April 26, 2023.

Email Alerts Receive free email-alerts when new articles cite this article. Sign up at:

http://ijssurgery.com/alerts

The International Journal of Sphing Surgerthttp://ijssurgery.com/ by guest on April 26, 2 2397 Waterbury Circle, Suite 1,

Aurora, IL 60504, Phone: +1-630-375-1432 


\section{Reliability of the Planned Pedicle Screw Trajectory versus the Actual Pedicle Screw Trajectory using Intra-operative 3D CT and Image Guidance}

Catherine A. Miller, MD, ${ }^{1}$ Charles G. Ledonio, MD, Matthew A. Hunt, MD, ${ }^{1}$ Farhan Siddiq, MD, ${ }^{3}$ David W. Polly Jr, MD ${ }^{2}$

${ }^{1}$ University of Minnesota Department of Neurosurgery, Minneapolis, MN, ${ }^{2}$ University of Minnesota Department of Orthopaedics, Minneapolis, MN, ${ }^{3} \mathrm{Jeffer-}$ son University Department of Neurosurgery, St. Mary Medical Center, Langhorne, PA

\section{Abstract}

\section{Background}

Technological advances, including navigation, have been made to improve safety and accuracy of pedicle screw fixation. We evaluated the accuracy of the virtual screw placement (Stealth projection) compared to actual screw placement (intra-operative O-Arm) and examined for differences based on the distance from the reference frame.

\section{Methods}

A retrospective evaluation of prospectively collected data was conducted from January 2013 to September 2013. We evaluated thoracic and lumbosacral pedicle screws placed using intraoperative $\mathrm{O}$-arm and Stealth navigation by obtaining virtual screw projections and intraoperative $\mathrm{O}$-arm images after screw placement. The screw trajectory angle to the midsagittal line and superior endplate was compared in the axial and sagittal views, respectively. Percent error and paired t-test statistics were then performed.

\section{Results}

Thirty-one patients with 240 pedicle screws were analyzed. The mean angular difference between the virtual and actual image in all screws was $2.17^{\circ} \pm 2.20^{\circ}$ on axial images and $2.16^{\circ} \pm 2.24^{\circ}$ on sagittal images. There was excellent agreement between actual and virtual pedicle screw trajectories in the axial and sagittal plane with ICC $=0.99$ $(95 \% \mathrm{CI}: 0.992-0.995)(\mathrm{p}<0.001)$ and ICC $=0.81(95 \% \mathrm{CI}: 0.759-0.855)(\mathrm{p}<0.001)$ respectively. When comparing thoracic and lumbar screws, there was a significant difference in the sagittal angulation between the two distributions. No statistical differences were found distance from the reference frame.

\section{Conclusion}

The virtual projection view is clinically accurate compared to the actual placement on intra-operative CT in both the axial and sagittal views. There is slight imprecision $\left(\sim 2^{\circ}\right)$ in the axial and sagittal planes and a minor difference in the sagittal thoracic and lumbar angulation, although these did not affect clinical outcomes. In general, we find that pedicle screw placement using intraoperative cone beam CT and navigation to be accurate and reliable, and as such have made it a routine part of our spine practice.

This study was approved by the University of Minnesota IRB (\#1303E30544).

KEYWORDS: PEDICLE SCREWS, ACCURACY, NAVIGATION

VOLUME 10 ARTICLE 38 DOI: $10.14444 / 3038$

\section{Introduction}

The use of screws for internal spinal fixation has been practiced since being described by King in 1948. ${ }^{1}$ Since that time, several techniques and instrumentation systems have been developed including the utilization of pedicle screws, which was initially reported by Boucher in $1959^{2}$ and further enhanced by Roy-Camille et al during the 1960 s. $^{3}$ Given their biomechanical superiority and ability to achieve greater correction of spinal deformities, pedicle screw placement has become routinely used for fixation and fusion of the thoracolumbar spine. ${ }^{4}$ Since the inception of pedicle screws for spinal stabilization, various techniques have been used to guide and verify screw placement. ${ }^{5,6}$ Examples of these tech- 
niques include the use of anatomic landmarks, ${ }^{7}$ laminotomy for palpation of the pedicle, plain radiography, fluoroscopic imaging (standard or image guidance), ${ }^{8,9}$ and CT image guidance. ${ }^{10-27}$ Extensive literature has been published describing the technique, benefits, and drawbacks of each method, as well as comparisons between different approaches. ${ }^{28-45}$

With its increasing use has come a multitude of studies regarding the safety of this technique. Proper screw placement is imperative in order to avoid complications such as CSF leak, and pedicle fractures. ${ }^{46-48}$ Serious complications such vascular, visceral, and neurologic injury are rare, however screw malposition is a more common complication, with a cited incidence of $0-42 \%{ }^{46-50}$ It is also necessary to provide a strong stable construct by minimizing screw pullout, breakage, and late spinal instability. ${ }^{51,52}$ Each of these indications is directly related to the accuracy of pedicle screw placement.

Technological advances, including navigation, have been made to improve safety and accuracy of pedicle screw fixation. Several studies and meta-analyses have shown that the accuracy of pedicle screw placement is variable even with these new technologies. ${ }^{48-50,53-57}$ Kosmopoulos and Schizas ${ }^{50}$ reviewed 130 studies regarding 37,337 pedicle screws and found that screws placed with navigation had an accuracy of 95.1\% while those without navigation were accurate $90.3 \%$. Verma et al. ${ }^{57}$ also showed a significant difference between accuracy of navigated vs non-navigated screws, $93.3 \%$ vs $84.7 \%$, respectively. Tian et al. ${ }^{55,56}$ has published several meta-analyses which show that navigation has a higher accuracy when compared to conventional methods. More recent meta-analyses have focused on comparing individual navigation methods rather than pooling all navigated screws together. Shin et al. ${ }^{54}$ investigated computer navigation compared to freehand screw placement and concluded that the computer navigated screws had considerably less risk of cortical perforation. In Mason et al. ${ }^{53}$ meta-analysis, they complied data from over 30 studies and 9000 pedicle screws and found that conventional fluoroscopy had an accuracy of $63.1 \%, 2 \mathrm{D}$ navigation had $84.3 \%$, and 3D navigation was the most accurate with $95.5 \%$. Additionally, Gelalis et al. ${ }^{49}$ and Tang et al. ${ }^{48}$ performed similar analyses and both de- termined that navigation provides a higher accuracy of pedicle screw placement.

We report our experience in comparing the virtual screw placement as recorded by the navigation system during screw placement to the actual screw placement seen on intraoperative CT scanning to determine the "as used" accuracy and reliability of the $\mathrm{O}$-arm imaging and Stealth navigation system for the thoracic and lumbosacral spine (Figure 1).

\section{Materials and Methods}

\section{Patient population}

A retrospective evaluation of prospectively collected data was conducted from January 2013 to September 2013 after obtaining approval from the institutional review board. Study inclusion criteria: consecutive patients who underwent thoracic or lumbosacral pedicle screw placement using O-arm and Stealth navigation during the study period at our university were evaluated. Only patients who had virtual as well as actual screw placement data were then included in this study. Any patient without a virtual projection for each screw and a post-instrumentation intraoperative CT scan or whose images were of poor quality were excluded.

\section{Surgical techniques and navigation setup}

After induction of general anesthesia, the patients were placed prone on a Jackson table and standard surgical exposure of the treated segment of spine is completed. Neuromonitoring was used in deformity correction cases. Screw stimulation was not performed and did not influence screw changes. Any necessary hardware removal was performed prior to the initial CT scan. A reference frame was attached to a spinous process and the sterilely draped $\mathrm{O}$-arm (Medtronic Inc., Louisville, CO) brought in to obtain an intraoperative CT scan. After the scan, the Oarm was kept sterile and moved toward the head of the bed. The CT scan was transferred to the Stealth system (Medtronic Inc.) to be used for navigation (Figure 2). The positions of the navigated instruments in relation to the reference frame were projected on the axial, coronal, and sagittal images acquired from the CT scan. Precision of the navigation is checked periodically by positioning a navigated probe 
on a known anatomic landmark such as a spinous process.

The remaining pedicle screws were placed in the following manner. Using anatomic landmarks and verifying with navigation, the pedicle was identified and a trajectory planned. A virtual screw projection was laid along this trajectory and a screen snapshot is taken using the Stealth system (Figure 3). Using a highspeed drill or awl, a track was made through the pedicle. The hole was probed for breaches, tapped, probed again, and a screw placed with navigated instruments (Figure 4). Optimal screw diameter and length were measured using the Stealth system. If additional screws were to be placed in subsequent levels beyond the initial scan field of view, the reference frame was moved and the above process repeated for those screws. At the discretion of the operating surgeon, any concerning screws identified on the second confirmation CT were removed or redirected prior to closure. Previously, we have reported a 3\% screw change rate on 2500 screws. ${ }^{37}$

For two patients, a minimally invasive technique was used. A percutaneous reference frame was placed in the posterior iliac spine and 3D images obtained and
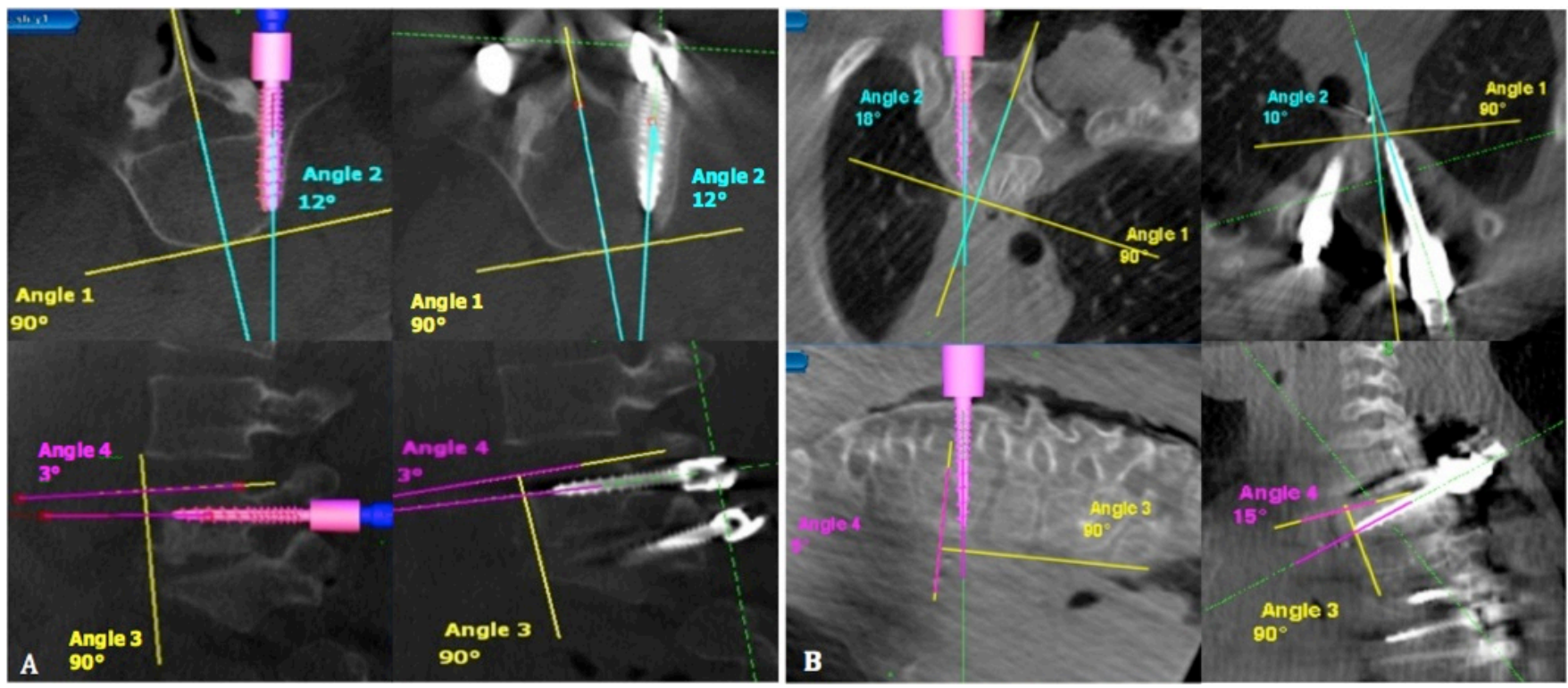

Fig. 1. Axial and sagittal images of the virtual screw and actual screw angles relative to the mid sagittal line and superior endplate, respectively. (A) Example of most accurate screw placement (B) Example of least accurate screw placement.

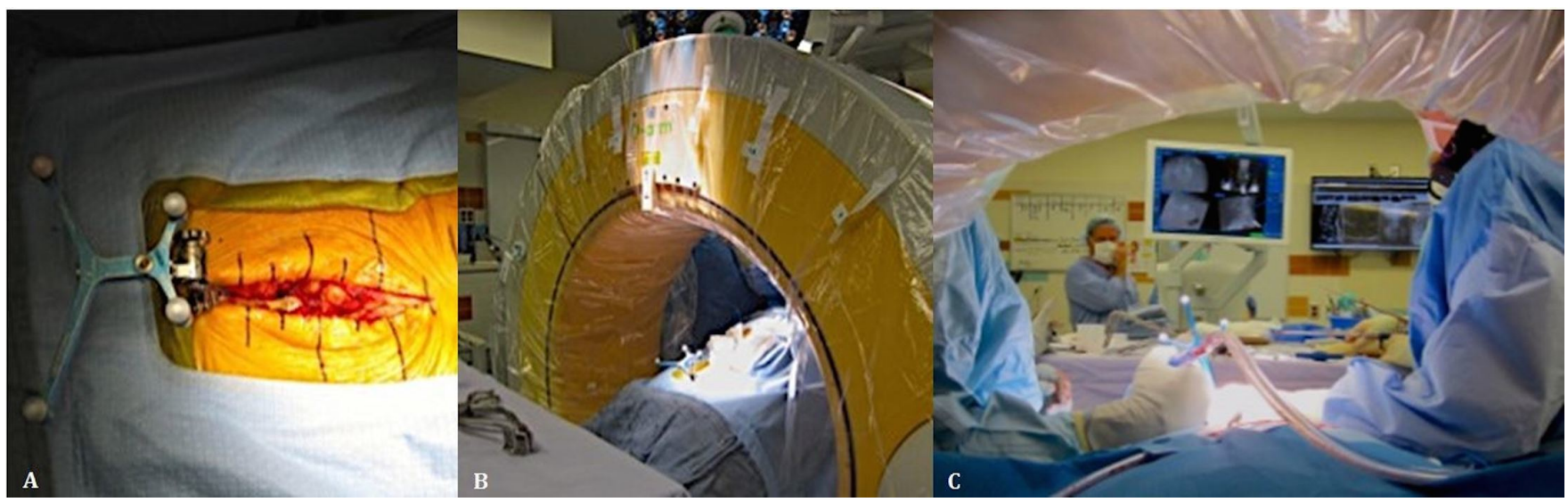

Fig. 2. (A) The patient is in a prone position, and a reference frame is attached to a spinous process. (B) The O-arm is brought into the field and a CT scan obtained. (C) The position of the navigated instruments is projected onto the CT images on a monitor visible to the surgeon. 
transferred to the Stealth image-guided workstation. Navigation was used to identify the skin entry points and several small paramedian incisions were made. Utilizing image-guided technology, a sharp probe was delivered into the pedicle and a K-wire placed. The pedicle was tapped and a screw was placed using navigated instruments. A second intraoperative CT scan was performed after all the screws were placed to confirm screw position (Figure 5).

\section{Statistical Method}

One individual not involved in the surgical procedure reviewed all virtual screw projections, intraoperative CT scan after screw placement, and operative reports. The screw trajectory angle to the midsagittal line and superior endplate was compared in the axial

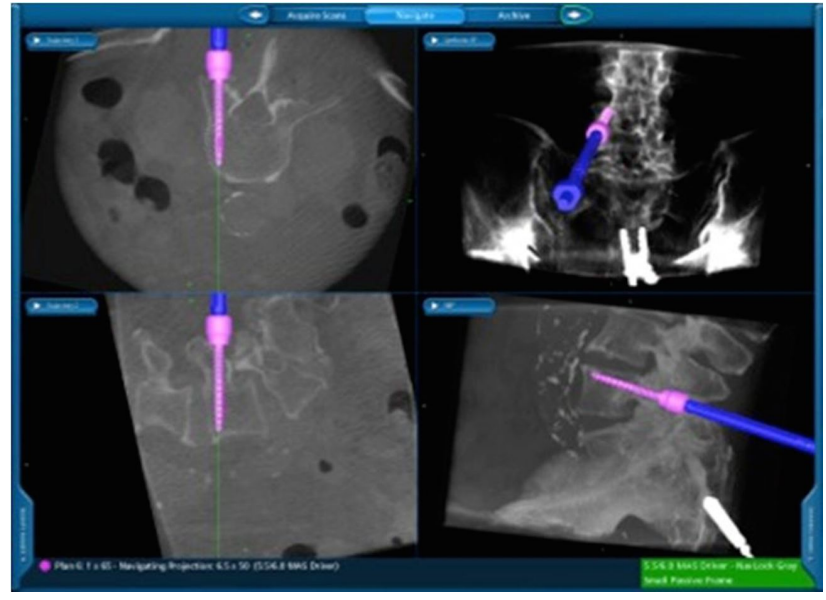

Fig. 3. Image of the Stealth Station navigation screen showing the axial, sagittal, and coronal virtual screw projection.

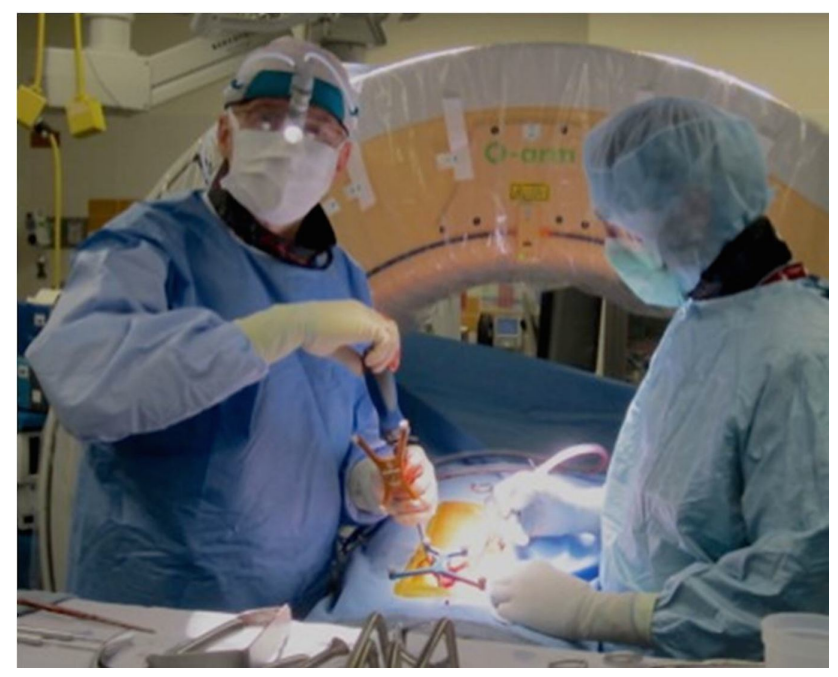

Fig. 4. Using a navigated screwdriver, the surgeon is able visualize the real-time trajectory of the screw on the Stealth Station screen during placement. and sagittal views for both virtual and actual projections, respectively (Figure 1) using the Surgimap software (Nemaris Inc., New York, NY). Mean angle difference was calculated between the virtual and actual angle in both axial and sagittal planes. Percent error calculations were then performed. To test reliability of the virtual pedicle screw trajectory compared to the actual screw trajectory, intra-class correlation coefficient was calculated (SPSS version 20). Accuracy of screws placed in the thoracic spine was compared to those in lumbosacral spine using t-tests. The relationship between the accuracy and distance from the reference frame was also investigated. Results were considered statistically significant at a probability value of $<0.05$.

\section{Results}

Between January 2013 and September 2013, 153 patients underwent posterior thoracolumbar spinal instrumentation using the $\mathrm{O}$-arm and Stealth navigation system at our institution. We routinely use navigation for screw placement and have redundant systems in place, so a system malfunction is quite rare $(<1 \%)$. Thirty-one consecutive patients (17 female, 14 male; age range 6-85 years) who had all necessary imaging were included in the study. A total of 240 screws were placed from $\mathrm{T} 1$ to $\mathrm{S} 1$, with 146 screws placed in the thoracic spine and 94 placed in the lumbosacral spine. Two cases used a percutaneous technique and twenty-nine were open surgeries. Surgeries were performed for a variety of indications including trauma, degenerative disease, scoliosis, and pseudarthrosis (Table 1). No vascular, visceral, or neurologic complication occurred in any of these cases. Three screws $(3 / 240=1.25 \%)$ were revised intraoperatively at the discretion of the operating surgeon

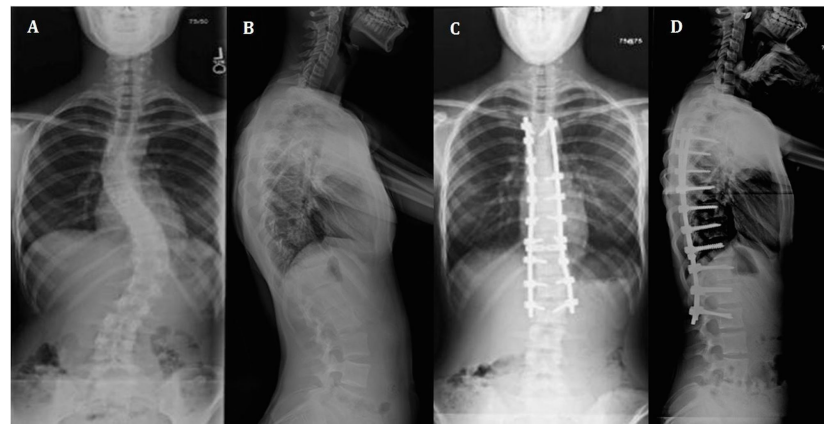

Fig. 5. AP and lateral spinal preoperative (A, B) and postoperative (C, D) $\mathrm{x}$-rays after a Stealth guided posterior spinal instrumentation. 
as they were noted to have breached the cortical surface on intraoperative CT scan (Figure 6). Two screws were removed as the pedicles were so diminutive as to not accept a redirected screw and one screw was exchanged for a shorter screw at the same trajectory. Axial and sagittal differences for these screws ranged from $5-8^{\circ}$ and $2-10^{\circ}$, respectively. One screw was in a patient with congenital scoliosis and two were in patients with idiopathic scoliosis.

In the 122 excluded patients out of the 153 total procedures, (53 male, 69 female; ages 3-80), 977 screws

\begin{tabular}{|c|c|}
\hline \multicolumn{2}{|l|}{ Patient Demographics } \\
\hline Mean age (range), yr & $44(6-85)$ \\
\hline \multicolumn{2}{|l|}{ Sex, no. (\%) } \\
\hline Female & $17(55)$ \\
\hline Male & $14(45)$ \\
\hline \multicolumn{2}{|l|}{ Primary Diagnosis, no. (\%) } \\
\hline Degenerative disk disease & $8(26)$ \\
\hline Scoliosis & $7(23)$ \\
\hline Spondylolithesis & $6(19)$ \\
\hline Pseudarthrosis & $3(10)$ \\
\hline Trauma & $3(10)$ \\
\hline Kyphosis & $2(6)$ \\
\hline Tumor/metastatic disease & $2(6)$ \\
\hline \multicolumn{2}{|l|}{ Fusion procedure, no (\%) } \\
\hline PSF & $16(52)$ \\
\hline TLIF & $7(22)$ \\
\hline Combined AP & $4(13)$ \\
\hline Combined TLIF/PSF & $4(13)$ \\
\hline
\end{tabular}

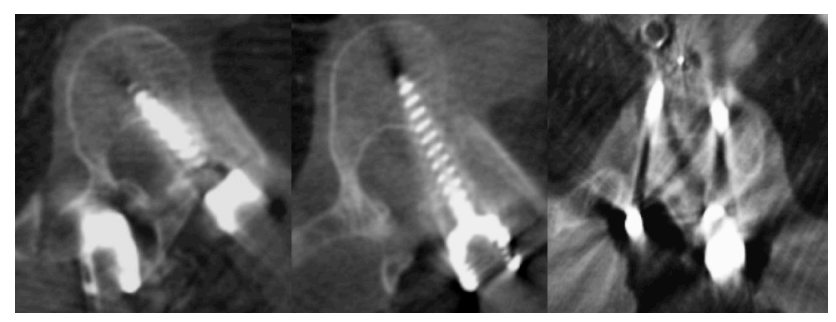

Fig. 6. Axial intraoperative CT scan of the three pedicle screws which were removed or revised. Two screws breached medially and one screw was too long. were placed. Thirty-nine of these surgeries were revisions and five patients required future revisions four were fusion extension for adjacent segment degeneration and one was performed for pseudoarthrosis and loosening of hardware. No screws were revised for suboptimal positioning in the subsequent surgeries. Eighteen screws were revised or removed during the index surgery $(18 / 977=1.8 \%)$ in fifteen surgeries for scoliosis (10), pseudarthrosis (2), spondylolithesis (2), and trauma (1). Reasons for screw revision included too long of screw (5), fixed screw exchanged for polyaxial screw (3), screw pullout during compression due to poor bone quality (2), misalignment with rest of construct (2), fracture of screw head (1), and poor placement (5). In two screw revisions for poor placement, there was a $5^{\circ}$ and $7^{\circ}$ difference from an ideal pedicle screw, as a virtual snapshot was not available for comparison. We defined ideal screw position as a screw positioned in the center of the pedicle with no cortical breach. Two screws were replaced for sagittal deviations which were not measureable on the postplacement axial CT scans and one screw was noted to be revised in an operative report, however the specific screw was not reported.

The screws were divided into individual spinal levels and the mean angular difference and percent error calculated for each level. Figure 1 illustrates two screw examples - the most accurate $\left(0^{\circ}\right.$ difference in axial and sagittal planes) and the least accurate $\left(8^{\circ}\right.$ difference in axial plane, $10^{\circ}$ difference in sagittal plane). The mean angular difference between the virtual and actual image in all screws was $2.17^{\circ} \pm 2.20^{\circ}$ on axial images and on sagittal images was $2.16^{\circ} \pm$ $2.24^{\circ}$. The axial and sagittal angular differences (\%error) were the same at $1.1 \%$ and $1.2 \%$, respectively (Table 2). The ICC in the axial images was 0.994 (95\% CI: 0.991-0.996, p < 0.001) and for the sagittal images was 0.813 (95\% CI: 0.739-0.867, p< 0.001), indicating excellent test-retest reliability.

The screws were then separated into thoracic versus lumbosacral screws to determine if there was a significant difference in accuracy. The mean angular difference for the thoracic screws was $2.14^{\circ}$ and $1.88^{\circ}$ in the axial and sagittal images, with percent error of $1.09 \%$ and $1.02 \%$ respectively. The lumbosacral screw 
mean angular difference was $2.22^{\circ}$ in axial images and $2.61^{\circ}$ in sagittal images with percent errors of $1.12 \%$ and $1.41 \%$, respectively. No statistical difference was found between the axial thoracic and lumbosacral screws accuracies $(\mathrm{p}=0.877)$, however the difference was significant in the sagittal screws accuracies $(\mathrm{p}=0.024)$ (Table 3$)$.

We also investigated if the distance from the reference frame affected accuracy. All screws were separated into number of spinal levels from the reference frame. Out of the 240 screws placed, only 18 were placed more than 5 vertebral levels away from the reference frame. The mean angular difference and percent error are listed for each subgroup in Table 4.
The accuracy of screw placement in axial and sagittal planes was analyzed in relation to distance from reference frame. There was no statistically significant difference in accuracy of pedicle screws distanced up to 10 vertebral segments away from the reference frame.

\section{Discussion}

In this study, we evaluated the accuracy of pedicle screw placement using the $\mathrm{O}$-arm and Stealth navigation. We compared virtual placement as recorded by the navigation system and actual screw placement as measured by the intraoperative CT imaging in axial and sagittal planes obtained during surgery in the

\begin{tabular}{|c|c|c|c|c|c|c|c|c|c|}
\hline \multirow{2}{*}{ Level } & \multirow{2}{*}{$\begin{array}{l}\text { No. of } \\
\text { screws }\end{array}$} & \multicolumn{4}{|r|}{ Axial } & \multicolumn{4}{|r|}{ Sagittal } \\
\hline & & $\begin{array}{l}\text { Mean virtual } \\
\text { angle }\left({ }^{\circ}\right)\end{array}$ & $\begin{array}{r}\text { Mean actual } \\
\text { angle }\left({ }^{\circ}\right)\end{array}$ & $\begin{array}{r}\text { Mean angle differ- } \\
\text { ence }\left({ }^{\circ}\right)\end{array}$ & $\begin{array}{r}\text { Percent } \\
\text { error }\end{array}$ & $\begin{array}{r}\text { Mean virtual } \\
\text { angle }\left(^{\circ}\right)\end{array}$ & $\begin{array}{r}\text { Mean actual } \\
\text { angle }\left(^{\circ}\right)\end{array}$ & $\begin{array}{r}\text { Mean angle differ- } \\
\text { ence }\left({ }^{\circ}\right)\end{array}$ & $\begin{array}{r}\text { Percent } \\
\text { error }\end{array}$ \\
\hline $\mathrm{T} 1$ & 9 & 22.4 & 21.2 & 2.56 & $1.25 \%$ & 4.56 & 1.78 & 3.00 & $1.59 \%$ \\
\hline $\mathrm{T} 2$ & 11 & 17.8 & 17.3 & 2.73 & $1.38 \%$ & 4.00 & 4.45 & 2.82 & $1.52 \%$ \\
\hline $\mathrm{T} 3$ & 11 & 15.5 & 14.8 & 3.27 & $1.66 \%$ & 2.45 & 2.18 & 2.09 & $1.14 \%$ \\
\hline $\mathrm{T} 4$ & 8 & 18.1 & 15.8 & 3.13 & $1.57 \%$ & 4.38 & 2.63 & 2.00 & $1.08 \%$ \\
\hline T5 & 15 & 16.1 & 15.1 & 2.53 & $1.30 \%$ & 3.47 & 2.47 & 1.93 & $1.04 \%$ \\
\hline T6 & 12 & 13.8 & 12.1 & 2.00 & $1.03 \%$ & 3.25 & 3.25 & 1.00 & $0.55 \%$ \\
\hline $\mathrm{T} 7$ & 12 & 12.8 & 12.3 & 2.00 & $1.04 \%$ & 4.17 & 3.33 & 1.83 & $0.99 \%$ \\
\hline $\mathrm{T} 8$ & 14 & 13.9 & 13.5 & 1.71 & $0.88 \%$ & 4.00 & 4.79 & 1.79 & $0.97 \%$ \\
\hline T9 & 15 & 13.1 & 13.3 & 1.40 & $0.73 \%$ & 3.20 & 4.20 & 1.67 & $0.91 \%$ \\
\hline $\mathrm{T} 10$ & 13 & 11.1 & 10.1 & 1.77 & $0.93 \%$ & 1.69 & 0.77 & 1.69 & $0.92 \%$ \\
\hline T11 & 16 & 9.9 & 9.4 & 1.94 & $1.02 \%$ & 5.69 & 5.38 & 1.69 & $0.91 \%$ \\
\hline $\mathrm{T} 12$ & 10 & 8.7 & 9.0 & 1.30 & $0.69 \%$ & 2.44 & 2.33 & 1.44 & $0.75 \%$ \\
\hline L1 & 11 & 15.1 & 14.4 & 1.64 & $0.84 \%$ & 3.91 & 4.18 & 1.91 & $1.03 \%$ \\
\hline L2 & 14 & 20.7 & 19.1 & 2.57 & $1.25 \%$ & 3.71 & 3.64 & 2.50 & $1.35 \%$ \\
\hline L3 & 12 & 18.8 & 18.7 & 2.00 & $1.00 \%$ & 4.58 & 3.67 & 1.75 & $0.95 \%$ \\
\hline L4 & 18 & 16.9 & 16.8 & 2.67 & $1.33 \%$ & 3.86 & 4.14 & 2.19 & $1.22 \%$ \\
\hline L5 & 22 & 14.6 & 14.8 & 2.55 & $1.29 \%$ & 3.05 & 4.32 & 2.45 & $1.34 \%$ \\
\hline $\mathrm{S} 1$ & 17 & 11.2 & 10.7 & 1.59 & $0.83 \%$ & 3.94 & 3.24 & 4.35 & $2.32 \%$ \\
\hline \multirow[t]{2}{*}{ Total } & 240 & 14.8 & 14.2 & 2.17 & 1.11 & 3.67 & 3.49 & 2.16 & $1.17 \%$ \\
\hline & & \multicolumn{4}{|c|}{$P$ value 0.0016} & \multicolumn{4}{|c|}{$\mathrm{P}$ value $=0.19$} \\
\hline
\end{tabular}


thoracic and lumbosacral spine. The results show that the virtual screw trajectory when compared to the actual trajectory had excellent and statistically significant test-retest reliability. There was no statistically significant difference between thoracic and lumbosacral screws in the axial plane, however greater imprecision was noted in the sagittal plane. Some of these differences may be attributed to the lumbar spine being more mobile than the thoracic spine. The sagittal plane also had greater imprecision in sacral screws, and may be related to the challenging angulation of the sacrum in some patients or interference with adjacent level screw heads. In the data evaluated for this study, we did not find any effect on accuracy of screw placement related to distance from the reference frame up to 10 levels. While this surprised our team, the outcome is likely a result of the limited numbers of levels studied and the small number of patients who had screws placed greater than 5 levels from the reference frame.

Despite extensive literature on the subject, there is no universal definition regarding the accuracy of screw placement, or consensus on how to assess for misplacement. This in part, may be responsible for the large variation in reported accuracy as there are no standardized evaluation methods. As Kosmopoulos and Schizas $^{50}$ noted in their meta-analysis, there are over 35 different approaches to assess the accuracy of pedicle screw placement. Many papers regarding pedicle screw accuracy use the presence or absence of cortical breaches as a marker of accuracy. ${ }^{58,59}$ In this study, we did not grade screws as these previous studies. We instead evaluated the precision of the navigation by calculating the difference between the virtual image and actual image when compared to midline and superior endplate in the axial and sagittal images, respectively. Oertel et $\mathrm{al}^{60}$ investigated the angular difference between the projected trajectory and the actual screw placement, but only in the axial plane. The difference in angulation calculated in their study was $2.8^{\circ} \pm 1.9^{\circ}$, which was similar to our data showing a difference of $2.17^{\circ} \pm 2.20^{\circ}$.

\begin{tabular}{|c|c|c|c|c|c|c|c|c|c|}
\hline \multirow{2}{*}{ Level } & \multirow{2}{*}{$\begin{array}{l}\text { No. of } \\
\text { screws }\end{array}$} & \multicolumn{4}{|r|}{ Axial } & \multicolumn{4}{|r|}{ Sagittal } \\
\hline & & $\begin{array}{l}\text { Mean virtual } \\
\text { angle }\left({ }^{\circ}\right)\end{array}$ & $\begin{array}{r}\text { Mean actual } \\
\text { angle }\left({ }^{\circ}\right)\end{array}$ & $\begin{array}{r}\text { Mean angle dif- } \\
\text { ference }\left({ }^{\circ}\right)\end{array}$ & $\begin{array}{r}\text { Percent } \\
\text { error }\end{array}$ & $\begin{array}{r}\text { Mean virtual } \\
\text { angle }\left({ }^{\circ}\right)\end{array}$ & $\begin{array}{r}\text { Mean actual } \\
\text { angle }\left({ }^{\circ}\right)\end{array}$ & $\begin{array}{r}\text { Mean angle dif- } \\
\text { ference }\left({ }^{\circ}\right)\end{array}$ & $\begin{array}{r}\text { Percent } \\
\text { error }\end{array}$ \\
\hline Thoracic & 146 & 14.1 & 13.4 & 2.14 & $1.10 \%$ & 3.63 & 3.26 & 1.88 & $1.02 \%$ \\
\hline Lumbosacral & 94 & 15.9 & $15.5-$ & 2.22 & $1.12 \%$ & 3.73 & 3.86 & 2.61 & $1.41 \%$ \\
\hline
\end{tabular}

Table 4. Angulation difference based on distance from reference frame.

\begin{tabular}{|c|c|c|c|c|c|c|c|c|c|}
\hline \multirow{2}{*}{$\begin{array}{l}\text { Level from refer- } \\
\text { ence frame }\end{array}$} & \multirow{2}{*}{$\begin{array}{l}\text { No. of } \\
\text { screws }\end{array}$} & \multicolumn{4}{|r|}{ Axial } & \multicolumn{4}{|r|}{ Sagittal } \\
\hline & & $\begin{array}{l}\text { Mean virtual } \\
\text { angle }\left({ }^{\circ}\right)\end{array}$ & $\begin{array}{r}\text { Mean actual } \\
\text { angle }\left({ }^{\circ}\right)\end{array}$ & $\begin{array}{r}\text { Mean angle dif- } \\
\text { ference }\left({ }^{\circ}\right)\end{array}$ & $\begin{array}{r}\text { Percent } \\
\text { error }\end{array}$ & $\begin{array}{r}\text { Mean virtual } \\
\text { angle }\left({ }^{\circ}\right)\end{array}$ & $\begin{array}{r}\text { Mean actual } \\
\text { angle }\left({ }^{\circ}\right)\end{array}$ & $\begin{array}{r}\text { Mean angle dif- } \\
\text { ference }\left({ }^{\circ}\right)\end{array}$ & $\begin{array}{r}\text { Percent } \\
\text { error }\end{array}$ \\
\hline 0 & 45 & 14.1 & 14.3 & 1.83 & $0.9 \%$ & 3.0 & 3.6 & 2.02 & $1.1 \%$ \\
\hline 1 & 64 & 16.5 & 16.6 & 1.50 & $0.8 \%$ & 3.8 & 3.2 & 1.50 & $1.4 \%$ \\
\hline 2 & 37 & 15.5 & 14.6 & 2.22 & $1.1 \%$ & 3.4 & 3.6 & 2.22 & $0.9 \%$ \\
\hline 3 & 34 & 19.2 & 18.1 & 2.44 & $1.2 \%$ & 4.5 & 4.0 & 2.44 & $0.9 \%$ \\
\hline 4 & 23 & 14.1 & 13.3 & 2.13 & $1.1 \%$ & 3.7 & 3.1 & 2.13 & $1.3 \%$ \\
\hline 5 & 19 & 18.4 & 17.3 & 2.68 & $1.3 \%$ & 2.2 & 1.4 & 2.68 & $1.3 \%$ \\
\hline 6 & 9 & 36.2 & 35.4 & 2.56 & $1.3 \%$ & 5.4 & 5.7 & 2.56 & $1.2 \%$ \\
\hline $7-10$ & 9 & 19.0 & 15.0 & 6.00 & $3.0 \%$ & 5.4 & 5.6 & 6.00 & $1.1 \%$ \\
\hline
\end{tabular}

Downloaded from http://ijssurgery.com/ by guest on April 26, 2023 
As noted previously, imaged guided pedicle screw placement via the O-arm and Stealth navigation systems is a routine practice at our institution. Both surgeons and staff have become experienced in its application and technique given its routine use. The $\mathrm{O}-$ arm system provides a reconstruction algorithm to develop a real time 3D image of the patient's anatomy and the Stealth system allows for manipulation of these images in the sagittal, axial, and coronal planes. There are several potential sources of error using this system. Statistical analysis of data from the manufacturer's formal bench testing reports that for its most commonly used navigation products, the registration technique has an error less than $2.3 \mathrm{~mm}$ (99\% confidence interval). In some patients with flexible curves, it is possible to "push" with the instruments and affect the navigation. This can be reduced through intermittent accuracy checks using known anatomic landmarks and being cognizant not to distort the spine with the instruments. Inadvertently touching or hitting the reference frame can also decrease the accuracy in all planes. Taking care to avoid striking the reference frame and frequent checks to ensure fixed placement of the frame on the spinous process can limit this risk. If any soft tissue is located between the tip of the probe and entry point during navigation, the screw length may be overestimated. This can be eliminated by confirming direct contact between the navigated tool and bone. The Stealth projected images of the screws are portrayed as a straight line but the actual trajectory may be slightly deviated given the polyaxial screw heads and screw/ screwdriver interface. It is important to ensure that the screws are loaded straight on the screwdriver and tightly attached to decrease any possible movement. Observer error in measurement may also effect the discrepancy in measurements, however all measurements were performed by a single investigator in a systematic manner. Any combination of possible sources of error can occur, and we have shown only a $2^{\circ}$ error with our standard operating technique.

There are several limitations noted for this study. At our institution, O-arm and intraoperative imaging have been used routinely used for pedicle screw instrumentation since 2007. Our staff and operating surgeons have become experienced users and results may differ compared to institutions where this sys- tem is not regularly used, as there is a learning curve associated with this technology. As this was not formally studied in a retrospective fashion, further data will require a prospective study with a larger cohort of patients, as the small number of patients limits the power of the study.

A large proportion of the patients $(122 / 153)$ who underwent spinal instrumentation during the designated time period were excluded from this study as they did not have the all of the necessary imaging, including both a screw projection for each screw placed and an intraoperative CT scan. For some patients the intraoperative post-instrumentation CT scan was not uploaded into our PACs system or if multiple scans were required for long constructs, not all of them were stored. The virtual screw projections rely on our system's representative to capture and save the virtual projection for every screw. During some portions of the surgery, screw placement may have outpaced the ability to capture some screw projections. The Stealth station also has a finite amount of memory and must be cleared to allow for additional cases - some virtual projection data may not have been saved prior to clearing the memory. It does not appear that there was any difference in the nature of the cases that were included or excluded. Since this was not a prospective study, our cohort is a sample where adequate data points were available to allow the complete review.

When reporting accuracy of a system, it is also necessary to determine what value is clinically significant which requires interpretation of the data. A difference may be found to be statistically significant, but may have little or no importance to the patient's symptoms or quality of life. ${ }^{61}$ The minimal clinically important difference (MCID) was originally defined by Jaeschke as "the smallest difference in score in the domain of interest which patients perceive as beneficial and which would mandate in the absence of troublesome side effects and excessive cost, a change in the patient's management". Over time the methodology to determine the MCID and the definition itself has varied, but it ultimately amounts to the smallest change that is considered important. ${ }^{62,63}$ Figure 7 demonstrates varying degrees of difference in the accuracy of a screw compared to an optimal tra- 
jectory. One could estimate from this diagram that the MCID for lumbar pedicle screw insertion compared to an ideal trajectory would be $<5^{\circ}$. This value would obviously be smaller in the thoracic spine where pedicles are smaller and there is a greater size variation. We have shown that a small difference of $2^{\circ}$ was not clinically significant as there were no returns to the operating room and no intraoperative neurologic, visceral, or vascular complications attributed to the difference. While patient reported outcomes are completed by all of our patients undergoing spinal surgery, the purpose of this study was to establish the immediate accuracy of navigation versus actual pedicle screw placement. Follow-up measures of fusion or patient outcomes are beyond the scope of this study especially given the difficulty in determining fusion status without the use of routine postoperative CT scans at 1 and 2 years, which is not routinely performed at our institution in asymptomatic patients.

\section{Conclusions}

The virtual projection view is clinically accurate compared to the actual placement on intra-operative $\mathrm{CT}$ in both the axial and sagittal views. There is slight imprecision $\left(\sim 2^{\circ}\right)$ in the axial and sagittal planes and a minor difference in the sagittal thoracic and lumbar angulation, although these did not affect clinical outcomes. In our cohort of patients, distance from the reference frame did not affect the accuracy

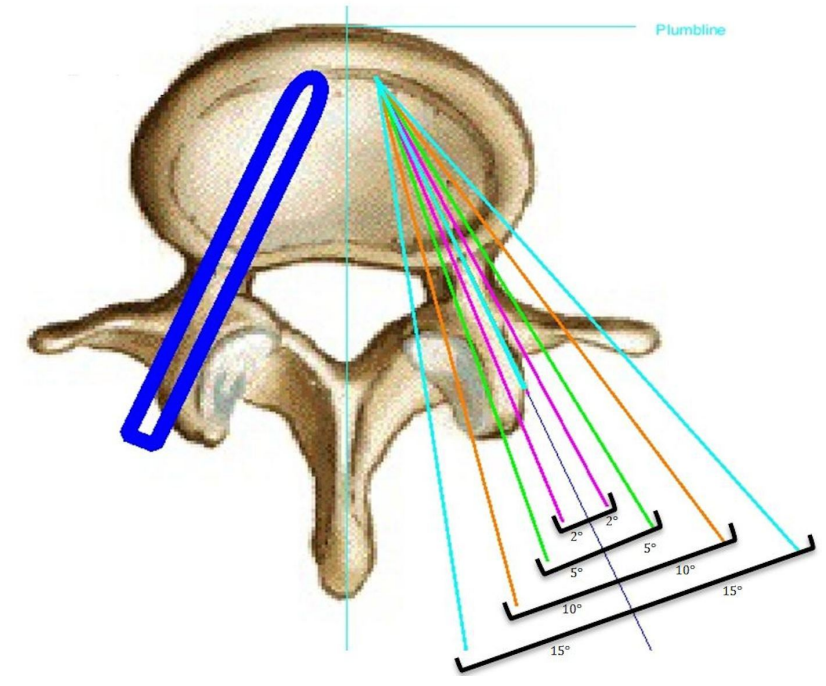

Fig. 7. Varying degrees of accuracy from an ideal screw trajectory in the lumbar spine. of the screw placement, however only a small number of patients had distances greater five levels from the frame. In general, we find that pedicle screw placement using intraoperative cone beam CT and navigation to be accurate and reliable, and as such have made it a routine part of our spine practice.

\section{References}

1. KING D. Internal fixation for lumbosacral fusion. J Bone Joint Surg Am. 1948;30A(3):560-565.

2. BOUCHER HH. A method of spinal fusion. $J$ Bone Joint Surg Br. 1959;41-B(2):248-259.

3. Roy-Camille R, Saillant G, Berteaux D, Salgado $\mathrm{V}$. Osteosynthesis of thoraco-lumbar spine fractures with metal plates screwed through the vertebral pedicles. Reconstr Surg Traumatol. 1976;15:2-16.

4. Ledonio CG, Polly DW,Jr, Vitale MG, Wang Q, Richards BS. Pediatric pedicle screws: Comparative effectiveness and safety: A systematic literature review from the scoliosis research society and the pediatric orthopaedic society of north america task force. J Bone Joint Surg Am. 2011;93(13):1227-1234. doi: 10.2106/JBJS.J.00678 [doi].

5. Manbachi A, Cobbold RS, Ginsberg HJ. Guided pedicle screw insertion: Techniques and training.

Spine J. 2014;14(1):165-179. doi: 10.1016/

j.spinee.2013.03.029 [doi].

6. Santos ER, Ledonio CG, Castro CA, Truong $\mathrm{WH}$, Sembrano JN. Validity of surgeon perception of navigated pedicle screw position: A cadaveric study. Spine (Phila Pa 1976). 2011;36(15):E1027-32. doi: 10.1097/BRS.0b013e3181ff5b73 [doi].

7. Parker SL, McGirt MJ, Farber SH, et al. Accuracy of free-hand pedicle screws in the thoracic and lumbar spine: Analysis of 6816 consecutive screws. Neurosurgery. 2011;68(1):170-8; discussion 178. doi: 10.1227/NEU.0b013e3181fdfaf4 [doi].

8. Amato V, Giannachi L, Irace C, Corona C. Accuracy of pedicle screw placement in the lumbosacral spine using conventional technique: Computed tomography postoperative assessment in 102 consecutive patients. J Neurosurg Spine. 2010;12(3):306-313. doi: 10.3171/2009.9.SPINE09261 [doi]. 9. Youkilis AS, Quint DJ, McGillicuddy JE, Papadopoulos SM. Stereotactic navigation for placement of pedicle screws in the thoracic spine. Neuro- 
surgery. 2001;48(4):771-8; discussion 778-9.

10. Beck M, Rotter R, Gradl G, et al. Reliability and consequences of intraoperative 3D imaging to control positions of thoracic pedicle screws. Arch Orthop Trauma Surg. 2012;132(10):1371-1377. doi: 10.1007/ s00402-012-1555-y [doi].

11. Dinesh SK, Tiruchelvarayan R, Ng I. A prospective study on the use of intraoperative computed tomography (iCT) for image-guided placement of thoracic pedicle screws. $B r J$ Neurosurg.

2012;26(6):838-844. doi: 10.3109/

02688697.2012.690917 [doi].

12. Hsieh JC, Drazin D, Firempong AO, Pashman R, Johnson JP, Kim TT. Accuracy of intraoperative computed tomography image-guided surgery in placing pedicle and pelvic screws for primary versus revision spine surgery. Neurosurg Focus. 2014;36(3):E2. doi: 10.3171/2014.1.FOCUS13525 [doi].

13. Jeswani S, Drazin D, Hsieh JC, et al. Instrumenting the small thoracic pedicle: The role of intraoperative computed tomography image-guided surgery. Neurosurg Focus. 2014;36(3):E6. doi: 10.3171/2014.1.FOCUS13527 [doi].

14. Larson AN, Polly DW,Jr, Guidera KJ, et al. The accuracy of navigation and 3D image-guided placement for the placement of pedicle screws in congenital spine deformity. J Pediatr Orthop.

2012;32(6):e23-9. doi: 10.1097/

BPO.0b013e318263a39e [doi].

15. Lee $\mathrm{MH}$, Lin $\mathrm{MH}$, Weng $\mathrm{HH}$, et al. Feasibility of intra-operative computed tomography navigation system for pedicle screw insertion of the thoracolumbar spine. J Spinal Disord Tech. 2012. doi: 10.1097/BSD.0b013e31828054c8 [doi]. 16. Ling JM, Dinesh SK, Pang BC, et al. Routine spinal navigation for thoraco-lumbar pedicle screw insertion using the $\mathrm{O}$-arm three-dimensional imaging system improves placement accuracy. J Clin Neurosci. 2014;21(3):493-498. doi: 10.1016/ j.jocn.2013.02.034 [doi].

17. Nottmeier EW, Seemer W, Young PM. Placement of thoracolumbar pedicle screws using threedimensional image guidance: Experience in a large patient cohort. J Neurosurg Spine. 2009;10(1):33-39. doi: 10.3171/2008.10.SPI08383 [doi]. 18. Papadopoulos EC, Girardi FP, Sama A, Sandhu HS, Cammisa FP,Jr. Accuracy of single-time, multi- level registration in image-guided spinal surgery. Spine J. 2005;5(3):263-7; discussion 268. doi: S1529-9430(04)00926-X [pii].

19. Patil S, Lindley EM, Burger EL, Yoshihara H, Patel VV. Pedicle screw placement with O-arm and stealth navigation. Orthopedics. 2012;35(1):e61-5. doi: 10.3928/01477447-20111122-15 [doi].

20. Rampersaud YR, Pik JH, Salonen D, Farooq S. Clinical accuracy of fluoroscopic computer-assisted pedicle screw fixation: A CT analysis. Spine (Phila Pa 1976). 2005;30(7):E183-90. doi:

00007632-200504010-00026 [pii].

21. Rivkin MA, Yocom SS. Thoracolumbar instrumentation with CT-guided navigation (O-arm) in 270 consecutive patients: Accuracy rates and lessons learned. Neurosurg Focus. 2014;36(3):E7. doi: 10.3171/2014.1.FOCUS13499 [doi].

22. Santos ER, Ledonio CG, Castro CA, Truong $\mathrm{WH}$, Sembrano JN. The accuracy of intraoperative $\mathrm{O}$-arm images for the assessment of pedicle screw postion. Spine (Phila Pa 1976). 2012;37(2):E119-25. doi: 10.1097/BRS.0b013e3182257cae [doi].

23. Scheufler KM, Franke J, Eckardt A, Dohmen H. Accuracy of image-guided pedicle screw placement using intraoperative computed tomography-based navigation with automated referencing. part II: Thoracolumbar spine. Neurosurgery.

2011;69(6):1307-1316. doi: 10.1227/

NEU.0b013e31822ba190 [doi].

24. Sembrano JN, Santos ER, Polly DW,Jr. New generation intraoperative three-dimensional imaging (O-arm) in 100 spine surgeries: Does it change the surgical procedure? J Clin Neurosci.

2014;21(2):225-231. doi: 10.1016/j.jocn.2013.04.011 [doi].

25. Takahashi J, Hirabayashi H, Hashidate H, Ogihara N, Kato H. Accuracy of multilevel registration in image-guided pedicle screw insertion for adolescent idiopathic scoliosis. Spine (Phila Pa 1976).

2010;35(3):347-352. doi: 10.1097/

BRS.0b013e3181b77f0a [doi].

26. Tormenti MJ, Kostov DB, Gardner PA, Kanter AS, Spiro RM, Okonkwo DO. Intraoperative computed tomography image-guided navigation for posterior thoracolumbar spinal instrumentation in spinal deformity surgery. Neurosurg Focus. 2010;28(3):E11. doi: 10.3171/2010.1.FOCUS09275 [doi]. 
27. Van de Kelft E, Costa F, Van der Planken D, Schils F. A prospective multicenter registry on the accuracy of pedicle screw placement in the thoracic, lumbar, and sacral levels with the use of the O-arm imaging system and StealthStation navigation. Spine (Phila Pa 1976). 2012;37(25):E1580-7. doi: 10.1097/ BRS.0b013e318271b1fa [doi].

28. Alhabib H, Nataraj A, Khashab M, Mahood J, Kortbeek F, Fox R. Pedicle screw insertion in the thoracolumbar spine: Comparison of 4 guidance techniques in the intact cadaveric spine. J Neurosurg Spine. 2011;14(5):664-669. doi: 10.3171/ 2010.11.SPINE10177 [doi].

29. Allam Y, Silbermann J, Riese F, Greiner-Perth

R. Computer tomography assessment of pedicle screw placement in thoracic spine: Comparison between free hand and a generic 3D-based navigation techniques. Eur Spine J. 2013;22(3):648-653. doi: 10.1007/s00586-012-2505-7 [doi].

30. Bandela JR, Jacob RP, Arreola M, Griglock TM, Bova F, Yang M. Use of CT-based intraoperative spinal navigation: Management of radiation exposure to operator, staff, and patients. World Neurosurg. 2013;79(2):390-394. doi: 10.1016/j.wneu.2011.05.019 [doi].

31. Bledsoe JM, Fenton D, Fogelson JL, Nottmeier EW. Accuracy of upper thoracic pedicle screw placement using three-dimensional image guidance. Spine J. 2009;9(10):817-821. doi: 10.1016/

j.spinee.2009.06.014 [doi].

32. Fayyazi AH, Hugate RR, Pennypacker J, Gelb

DE, Ludwig SC. Accuracy of computed tomography in assessing thoracic pedicle screw malposition. $J$

Spinal Disord Tech. 2004;17(5):367-371. doi: 00024720-200410000-00003 [pii].

33. Hart RA, Hansen BL, Shea M, Hsu F, Anderson GJ. Pedicle screw placement in the thoracic spine: A comparison of image-guided and manual techniques in cadavers. Spine (Phila Pa 1976).

2005;30(12):E326-31. doi: 00007632-200506150-00025 [pii].

34. Kotani T, Akazawa T, Sakuma T, et al. Accuracy of pedicle screw placement in scoliosis surgery: A comparison between conventional computed tomography-based and O-arm-based navigation techniques. Asian Spine J. 2014;8(3):331-338. doi: 10.4184/asj.2014.8.3.331 [doi].
35. Laine T, Schlenzka D, Makitalo K, Tallroth K, Nolte LP, Visarius H. Improved accuracy of pedicle screw insertion with computer-assisted surgery. A prospective clinical trial of 30 patients. Spine (Phila Pa 1976). 1997;22(11):1254-1258.

36. Laine T, Lund T, Ylikoski M, Lohikoski J, Schlenzka D. Accuracy of pedicle screw insertion with and without computer assistance: A randomised controlled clinical study in 100 consecutive patients. Eur Spine J. 2000;9(3):235-240.

37. Larson AN, Santos ER, Polly DW,Jr, et al. Pediatric pedicle screw placement using intraoperative computed tomography and 3-dimensional imageguided navigation. Spine (Phila Pa 1976).

2012;37(3):E188-94. doi: 10.1097/

BRS.0b013e31822a2e0a [doi].

38. Lekovic GP, Potts EA, Karahalios DG, Hall G. A comparison of two techniques in image-guided thoracic pedicle screw placement: A retrospective study of 37 patients and 277 pedicle screws. J Neurosurg Spine. 2007;7(4):393-398. doi: 10.3171/SPI-07/ 10/393 [doi].

39. Luther N, Iorgulescu JB, Geannette C, et al. Comparison of navigated versus non-navigated pedicle screw placement in 260 patients and 1434 screws: Screw accuracy, screw size, and the complexity of surgery. J Spinal Disord Tech. 2013. doi: 10.1097/ BSD.0b013e31828af33e [doi].

40. Rahmathulla G, Nottmeier EW, Pirris SM, Deen HG, Pichelmann MA. Intraoperative imageguided spinal navigation: Technical pitfalls and their avoidance. Neurosurg Focus. 2014;36(3):E3. doi: 10.3171/2014.1.FOCUS13516 [doi].

41. Shin MH, Ryu KS, Park CK. Accuracy and safety in pedicle screw placement in the thoracic and lumbar spines : Comparison study between conventional C-arm fluoroscopy and navigation coupled with O-arm(R) guided methods. J Korean Neurosurg Soc. 2012;52(3):204-209. doi: 10.3340/

jkns.2012.52.3.204 [doi].

42. Silbermann J, Riese F, Allam Y, Reichert T, Koeppert H, Gutberlet M. Computer tomography assessment of pedicle screw placement in lumbar and sacral spine: Comparison between free-hand and Oarm based navigation techniques. Eur Spine J. 2011;20(6):875-881. doi: 10.1007/s00586-010-1683-4 [doi]. 
43. Smith HE, Welsch MD, Sasso RC, Vaccaro AR. Comparison of radiation exposure in lumbar pedicle screw placement with fluoroscopy vs computerassisted image guidance with intraoperative threedimensional imaging. J Spinal Cord Med. 2008;31(5):532-537.

44. Tabaraee E, Gibson AG, Karahalios DG, Potts EA, Mobasser JP, Burch S. Intraoperative cone beam-computed tomography with navigation (OARM) versus conventional fluoroscopy (C-ARM): A cadaveric study comparing accuracy, efficiency, and safety for spinal instrumentation. Spine (Phila Pa 1976). 2013;38(22):1953-1958. doi: 10.1097/ BRS.0b013e3182a51d1e [doi]. 45. Waschke A, Walter J, Duenisch P, Reichart R, Kalff R, Ewald C. CT-navigation versus fluoroscopyguided placement of pedicle screws at the thoracolumbar spine: Single center experience of 4,500 screws. Eur Spine J. 2013;22(3):654-660. doi: 10.1007/s00586-012-2509-3 [doi].

46. Gautschi OP, Schatlo B, Schaller K, Tessitore E. Clinically relevant complications related to pedicle screw placement in thoracolumbar surgery and their management: A literature review of 35,630 pedicle screws. Neurosurg Focus. 2011;31(4):E8. doi: 10.3171/ 2011.7.FOCUS11168 [doi].

47. Lonstein JE, Denis F, Perra JH, Pinto MR, Smith MD, Winter RB. Complications associated with pedicle screws. J Bone Joint Surg Am. 1999;81(11):1519-1528.

48. Tang J, Zhu Z, Sui T, Kong D, Cao X. Position and complications of pedicle screw insertion with or without image-navigation techniques in the thoracolumbar spine: A meta-analysis of comparative studies. J Biomed Res. 2014;28(3):228-239. doi: 10.7555/JBR.28.20130159 [doi]. 49. Gelalis ID, Paschos NK, Pakos EE, et al. Accuracy of pedicle screw placement: A systematic review of prospective in vivo studies comparing free hand, fluoroscopy guidance and navigation techniques. Eur Spine J. 2012;21(2):247-255. doi: 10.1007/ s00586-011-2011-3 [doi].

50. Kosmopoulos V, Schizas C. Pedicle screw placement accuracy: A meta-analysis. Spine (Phila Pa 1976). 2007;32(3):E111-20. doi: 10.1097/ 01.brs.0000254048.79024.8b [doi].

51. Costa F, Villa T, Anasetti F, et al. Primary stabil- ity of pedicle screws depends on the screw positioning and alignment. Spine J. 2013;13(12):1934-1939. doi: 10.1016/j.spinee.2013.03.046 [doi].

52. Stauff MP, Freedman BA, Kim JH, Hamasaki T, Yoon ST, Hutton WC. The effect of pedicle screw redirection after lateral wall breach--a biomechanical study using human lumbar vertebrae. Spine J. 2014;14(1):98-103. doi: 10.1016/j.spinee.2013.03.028 [doi].

53. Mason A, Paulsen R, Babuska JM, et al. The accuracy of pedicle screw placement using intraoperative image guidance systems. J Neurosurg Spine. 2014;20(2):196-203. doi: 10.3171/ 2013.11.SPINE13413 [doi].

54. Shin BJ, James AR, Njoku IU, Hartl R. Pedicle screw navigation: A systematic review and metaanalysis of perforation risk for computer-navigated versus freehand insertion. J Neurosurg Spine. 2012;17(2):113-122. doi: 10.3171/2012.5.SPINE11399 [doi].

55. Tian NF, Xu HZ. Image-guided pedicle screw insertion accuracy: A meta-analysis. Int Orthop. 2009;33(4):895-903. doi: 10.1007/ s00264-009-0792-3 [doi].

56. Tian NF, Huang QS, Zhou P, et al. Pedicle screw insertion accuracy with different assisted methods: A systematic review and meta-analysis of comparative studies. Eur Spine J.

2011;20(6):846-859. doi: 10.1007/s00586-010-1577-5 [doi].

57. Verma R, Krishan S, Haendlmayer K, Mohsen A. Functional outcome of computer-assisted spinal pedicle screw placement: A systematic review and meta-analysis of 23 studies including 5,992 pedicle screws. Eur Spine J. 2010;19(3):370-375. doi: 10.1007/s00586-009-1258-4 [doi].

58. Gertzbein SD, Robbins SE. Accuracy of pedicular screw placement in vivo. Spine (Phila Pa 1976). 1990;15(1):11-14.

59. Rampersaud YR, Simon DA, Foley KT. Accuracy requirements for image-guided spinal pedicle screw placement. Spine (Phila Pa 1976).

2001;26(4):352-359.

60. Oertel MF, Hobart J, Stein M, Schreiber V, Scharbrodt W. Clinical and methodological precision of spinal navigation assisted by $3 \mathrm{D}$ intraoperative Oarm radiographic imaging. J Neurosurg Spine. 
2011;14(4):532-536. doi: 10.3171/

2010.10.SPINE091032 [doi].

61. Copay AG, Subach BR, Glassman SD, Polly

DW,Jr, Schuler TC. Understanding the minimum

clinically important difference: A review of concepts

and methods. Spine J. 2007;7(5):541-546. doi:

S1529-9430(07)00052-6 [pii].

62. Beaton DE, Boers M, Wells GA. Many faces of the minimal clinically important difference (MCID):

A literature review and directions for future research. Curr Opin Rheumatol. 2002;14(2):109-114.

63. Copay AG, Martin MM, Subach BR, et al. Assessment of spine surgery outcomes: Inconsistency of change amongst outcome measurements. Spine J. 2010;10(4):291-296. doi: 10.1016/

j.spinee.2009.12.027 [doi].

\section{Disclosures \& COI}

Dr. Ledonio receives support through the institution from Medtronic, Department of Defense, Scoliosis Research Society, and Orthopaedic Research \& Education Foundation.

\section{Corresponding Author}

Catherine A. Miller, MD, University of Minnesota Department of Neurosurgery, 420 Delaware St SE, MMC 96, Room D429 Mayo Building, Minneapolis, MN55455.mill5459@umn.edu.

Published 24 October 2016.

This manuscript is generously published free of charge by ISASS, the International Society for the Advancement of Spine Surgery. Copyright @ 2016 ISASS. To see more or order reprints or permissions, see http://ijssurgery.com. 